\title{
Computed tomography guided fine needle aspiration cytology of mass lesions of lung: Our experience
}

\author{
Mimi Gangopadhyay, \\ Indranil Chakrabarti, \\ Nilanjana Ghosh ${ }^{1}$, \\ Amita Giri \\ Departments of Pathology, \\ and ${ }^{1}$ Community Medicine, \\ North Bengal Medical College, \\ Sushrutanagar, Darjeeling, West \\ Bengal, India
}

\begin{abstract}
A B S T R A C T
Context: Computerized tomography (CT) guided fine needle aspiration cytology (FNAC) of lung lesions has rapidly emerged as a less-invasive, cheap, rapid and fairly accurate diagnostic aid in lung lesions. Aims: The purpose of this present study was to evaluate the effectiveness of CT-guided FNAC in the diagnosis of pulmonary mass lesions (both benign and malignant) and to determine the complication rate of this procedure. Settings and Design: We conducted an institution-based, prospective study on 127 patients who presented with pulmonary mass lesions. Materials and Methods: After proper consent was obtained, CT-guided transthoracic fine needle aspiration was done and their diagnoses were confirmed by appropriate methods. The results were analyzed statistically. Results: Out of 127 cases selected for the study, $59.8 \%$ were males while the rest were females. Cough was the most common symptom present in $71.2 \%$ cases, followed by weight loss (62.4\%). $21.2 \%$ cases were cytologically benign. Adenocarcinoma $(54.2 \%)$ was the commonest malignant tumor. FNAC provided at least $96 \%$ sensitivity and $100 \%$ specificity in diagnosing lung tumors. Among the benign lesions, specific diagnoses were obtained in $48.1 \%$ cases. Thus, altogether a specific diagnosis was obtained in 109 of 127 cases, i.e. $85.8 \%$. No major complication was noted. Conclusions: CT-guided FNAC is an extremely valuable and fairly accurate diagnostic aid of intrathoracic mass lesions, with a reasonable rate of complication.
\end{abstract}

Key words: Computed tomography guided fine needle aspiration cytology, lung, mass lesion

\begin{abstract}
Address for correspondence: Dr. Indranil Chakrabarti, Department of Pathology, North Bengal Medical College, Sushrutanagar, Darjeeling, West Bengal - 734 012, India. E-mail: drinch@rediffmail.com
\end{abstract}

\section{INTRODUCTION}

Guided fine needle aspiration cytology (FNAC) is often the first choice in lesions located in the mediastinum, pulmonary apex, medial upper lobe or periphery - especially small lesions of a few centimeters diameter. FNAC has particular value in those cases in which fiber-optic bronchoscopy and biopsy are non-diagnostic as in centrally placed pulmonary lesions. ${ }^{[1]}$ Recognition of the high accuracy rate of FNAC along with the simpler methods to treat its complications like pneumothorax has increased its popularity among clinicians, radiologists and pathologists. ${ }^{[2-6]}$ Even though FNAC has proven its role in the diagnosis of infections and other diffuse benign processes, the main indication remains the diagnoses of localized intrathoracic lesions suspected of

\begin{tabular}{|l|l|}
\hline \multicolumn{3}{|c|}{ Access this article online } \\
\hline Quick Response Code: & Website: \\
\hline & Www.jmpo.org \\
\hline
\end{tabular}

being malignant, particularly when less-invasive investigations prove to be negative ${ }^{[1]}$ The presence of pathologist at the time of the procedure leads to a reduction in the number of needle passes and may increase the overall sensitivity and accuracy of tumor typing. ${ }^{[7,8]}$ The purpose of this present study was to evaluate the effectiveness of Computerized Tomography (CT) guided FNAC in the diagnosis of pulmonary lesions and to determine the complication rate of this procedure.

\section{MATERIALS AND METHODS}

A prospective study was undertaken involving 127 patients who underwent CT-guided transthoracic fine needle aspiration from pulmonary mass lesions at a teaching hospital between June 2008 and July 2010. The inclusion criteria of this study were persons with mass lesion(s) in the lung clinically suspected to be pulmonary neoplasm and with sputum samples negative for acid-fast bacilli (AFB). A detailed clinical history including the demographic data, clinical history, personal history including smoking habit, contact history of tuberculosis, etc was obtained. FNAC was performed in the pulmonary lesions using a 22-gauge disposable lumbar puncture needle after obtaining proper 
informed consent. The procedure was performed in patients who did not have cough reflex or who coughed intractably. Arteriovenous malformation, aneurysm, pulmonary hypertension or histories of bleeding disorder were also ruled out beforehand. Premedication with midazolam was required in two cases - one elderly patient and the other a child with metastatic Hodgkin lymphoma. The smears were attained with the Papanicolaou stain after wet fixation and May-Grunwald-Giemsa (MGG) stain following dry fixation. The patients were kept in the radiology department for follow-up for a period of 2 hours after fine needle aspiration to keep track of any complication. A repeat CT scan was performed if indicated in case any complication developed. Histopathologic confirmation was done where necessary.

The study was approved by the Ethical Committee of the institution.

\section{RESULTS}

A total number of 127 cases were selected for the study, of which 76 were males $(59.8 \%)$ and the rest 51 were females $(40.15 \%)$. The age ranged was from 6 to 78 years, with an average of 58.71 years. Table 1 shows the clinical presentation of the patients. Cough was the most common symptom present in $71.2 \%$ cases, followed by weight loss (62.4\%). Radiologically, solitary mass lesion was present in $64.5 \%$ cases, more than one lesion in $7.8 \%$ cases and collapse/consolidation in $27.5 \%$ cases.

The results were classified in the following categories: 1 . benign specific, 2 . benign non-specific, 3 . malignant diagnostic, 4. suspicious of malignancy, and 5. inadequate for interpretation.

Twenty-seven cases $(21.2 \%)$ cases were cytologically benign, all of which were inflammatory in nature. As expected, malignancies formed the major group with 96 cases $(75.6 \%)$. Two cases $(1.6 \%)$ were suspected of malignancy and in another 2 cases $(1.6 \%)$ repeated aspirations were inadequate for cytopathological opinion [Table 2].

In the benign specific group $(n=13), 12$ cases yielded granulomas with background necrosis. Out of these 12 cases, 8 showed AFB with Ziehl-Neelsen (ZN) stain, and in the remaining 4 cases, polymerase chain reaction (PCR) for Mycobacterium tuberculosis was positive on the aspirated material. One case showed the presence of septate fungus branching at acute angles, confirming with the diagnosis of Aspergillus fumigatus [Figure 1]. The benign non-specific group $(n=14)$ included abscess in 2 and chronic non-specific inflammation in 12 cases [Table 3].
Thus, altogether a specific diagnosis was obtained in 109 of 127 cases, i.e. $85.8 \%$. Among the benign lesions, specific diagnoses were obtained in $48.1 \%$ cases.

Among the patients diagnosed with malignancy, the mean

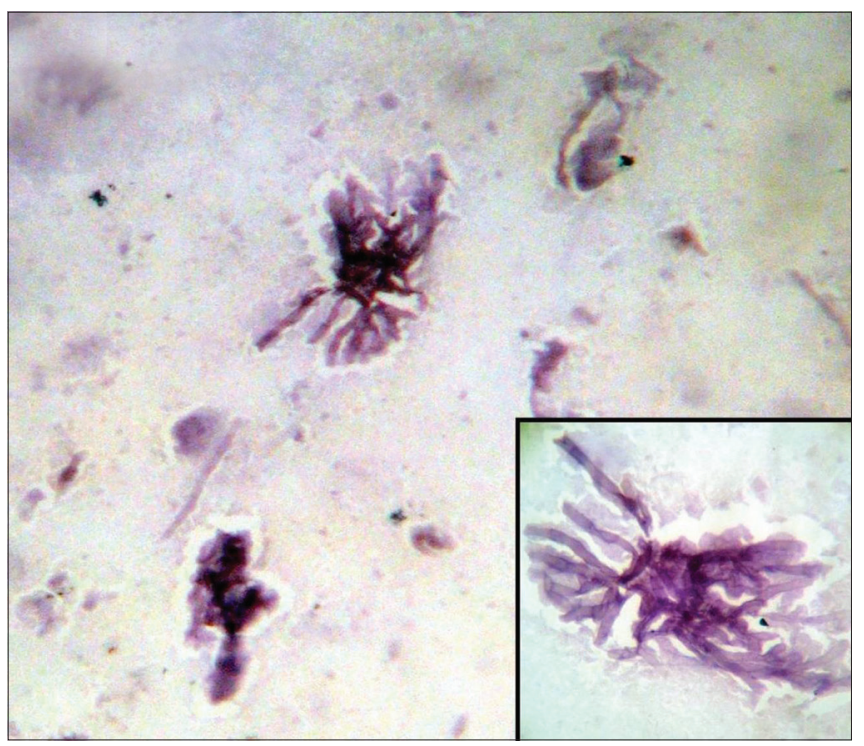

Figure 1: Photomicrograph showing septate, filamentous, branching hyphae of Aspergillus species (Papanicolaou stain, $\times 400$ magnification) Inset shows the septation and branching of hyphae in greater detail

\begin{tabular}{|c|c|c|}
\hline Symptoms & Number of cases $(N=127)$ & Percentage \\
\hline Chest pain & 56 & 44.8 \\
\hline Cough & 89 & 71.2 \\
\hline Weight loss & 78 & 62.4 \\
\hline Fever & 22 & 17.6 \\
\hline Hemoptysis & 42 & 33.6 \\
\hline
\end{tabular}

Table 2: Cytological diagnoses of pulmonary mass lesions

\begin{tabular}{lcc}
\hline Cytological categories & $\begin{array}{c}\text { Number of } \\
\text { cases }(\boldsymbol{N}=\mathbf{1 2 7})\end{array}$ & Percentage of cases \\
Benign specific & 13 & 10.2 \\
Benign non-specific & 14 & 11 \\
Malignancy & 96 & 75.6 \\
Suspicious for malignancy & 02 & 1.6 \\
Inadequate & 02 & 1.6 \\
\hline
\end{tabular}

\section{Table 3: Sub-categorization of cytologically benign lesions}

Benign conditions $(N=27)$

Number of cases

Tuberculosis

12

Aspergillus

01

Abscess

02

Chronic non-specific inflammation

12 
age group was 62.8 years (a range of 6-78 years) with male:female ratio of 10:1. Of the male patients, $80 \%$ were smokers while a meager $1.5 \%$ of females were smokers. Cough was the most common symptom present in $78 \%$ cases, followed by weight loss (64\%) and chest pain (54\%). Hemoptysis was seen in $35 \%$ of cases. The size of the lesions varied from 2 to $6 \mathrm{~cm}$. The 96 cases cytologically diagnosed as malignancy were confirmed by histopathology. There were two cases of suspected malignancy and these two cases where FNAC was non-diagnostic also turned out histopathologically to be malignant. Thus, FNAC could diagnose malignancy in 96 of 100 histopathologically proven malignant cases $(96 \%)$, while in 2 out $100(2 \%)$ cases it provided a suspicion of malignancy. Fine needle aspiration was inadequate in two cases due to the deep location of the tumors which were biopsied later on with bronchoscopic aid. There was no false-positive result. Hence, FNAC provided at least 96\% sensitivity and 100\% specificity in diagnosing lung tumors. The most common carcinoma as diagnosed by cytology was adenocarcinoma (54.2\%), followed by squamous cell carcinoma (25\%) and small cell carcinoma (8.3\%) [Table 4]. There were also three cases of non-Hodgkin lymphoma (NHL) and two cases of undifferentiated large cell carcinoma [Figure 2]. All the cases corroborated histopathologically except one case of cytologically diagnosed adenocarcinoma which later proved to be a small cell carcinoma. Thus, there was cytologicalhistopathologic corroboration in $98.9 \%$ cases, giving a high rate of diagnostic accuracy to the procedure of FNAC. There are no definite cytological criteria for distinguishing primary from secondary adenocarcinomas. We had one case each of metastatic hepatocellular carcinoma [Figure 3], metastatic fibrosarcoma [Figure 4] and malignant melanoma [Figure 5], all of which had a known primary site of tumor. We also made a diagnosis suggestive of bronchioloalveolar carcinoma (BAC) [Figure 6] which was later confirmed by histopathology.

\begin{tabular}{lcc}
\hline $\begin{array}{l}\text { Table 4: Cytological diagnoses of malignant } \\
\text { lesions }\end{array}$ & $\begin{array}{c}\text { Number of } \\
\text { cases }(\boldsymbol{N}=96)\end{array}$ & $\begin{array}{c}\text { Percentage } \\
\text { of cases }\end{array}$ \\
\hline Type of malignancy & 52 & 54.2 \\
Adenocarcinoma & 24 & 25 \\
Squamous cell carcinoma & 08 & 8.3 \\
Small cell carcinoma & 03 & 3.1 \\
Non-Hodgkin lymphoma & 02 & 2.1 \\
Large cell undifferentiated & 01 & 1.04 \\
Bronchioloalveolar carcinoma & 01 & 1.04 \\
Fibrosarcoma & 01 & 1.04 \\
Hodgkin lymphoma & 01 & 1.04 \\
Plasmacytoma & 01 & 1.04 \\
Neuroendocrine carcinoma & 01 & 1.04 \\
Seminoma & 01 & 1.04 \\
Melanocarcinoma & & \\
\hline
\end{tabular}

\section{DISCUSSION}

Fine needle aspiration is generally applied to localized lesions of lung, its use being limited to diffuse parenchymal disease. The main objective of guided FNAC is to diagnose malignancy although it can be used for definitive diagnosis of some benign neoplasms and infections such as Kochs. ${ }^{\left[{ }^{[]}\right.}$ Among the imaging modalities, CT is the most popular. ${ }^{[10]}$ Other modalities include fluoroscopy and ultrasonography. In the present study, there was a male preponderance with a male:female ratio of 1.49:1. Among the FNAC proven cases of malignancy, this difference was even more evident with a male:female ratio of 10:1. This difference is explained on the basis of higher incidence of predisposing factors like smoking, chronic obstructive pulmonary disease (COPD) and alcoholism in males. ${ }^{[1]}$ Material obtained from repeat aspirations of four cases presumptive of tuberculosis in which AFB was not found were sent for tuberculosis PCR. All of these cases gave positive results. Bailey et al. ${ }^{[12]}$ diagnosed 28 out of 34 cases of tuberculosis by either Auramine Rhodamine fluorescence or positive culture. AFB was seen in only $38 \%$ cases. Gong et al. found TB PCR to be $80 \%$ sensitive compared to $40 \%$ sensitivity of $\mathrm{ZN}$ staining in FNA material. ${ }^{[13]}$ FNAC was also repeated in one out of the two cases reported as suspicious of malignancy, but was not beneficial. Repeated aspiration was also of no use in the two cases where inadequate material was obtained in the first instance. Various studies have shown the rate of inadequate sampling to vary from 8.8 to $25.4 \% .{ }^{[14,15]}$ The single case where acute angled branching, parallel cell walls and septae were aspirated was diagnosed as Aspergillus and was later confirmed by culture.

Literature reveals that $70 \%$ of the primary lung cancers are diagnosed as non-small cell carcinomas, whereas small cell carcinomas are found to comprise around $20 \%$ of all primary lung tumors. ${ }^{[16]}$ In this series, the same pattern was observed. In the non-small cell group of carcinomas, adenocarcinoma was the commonest comprising $54.2 \%$ of cases. Though squamous cell carcinoma was used to be considered the commonest lung tumor, studies indicate that adenocarcinomas may have overtaken it in incidence. ${ }^{[17]}$

There are no definite cytological criteria for distinguishing primary from secondary adenocarcinomas, although there may be features indicative of a particular organ of origin. ${ }^{[18]}$ Immunostaining for TTF-1 is useful as it is the best single marker for primary pulmonary adenocarcinoma.

We got one case of BAC which is a subgroup of adenocarcinoma. In the WHO classification, BAC has been defined as a tumor without tissue or stromal invasion. ${ }^{[19]}$ So, FNAC cannot provide a specific diagnosis. In our cases, we got cells with minimal pleomorphism and intranuclear 


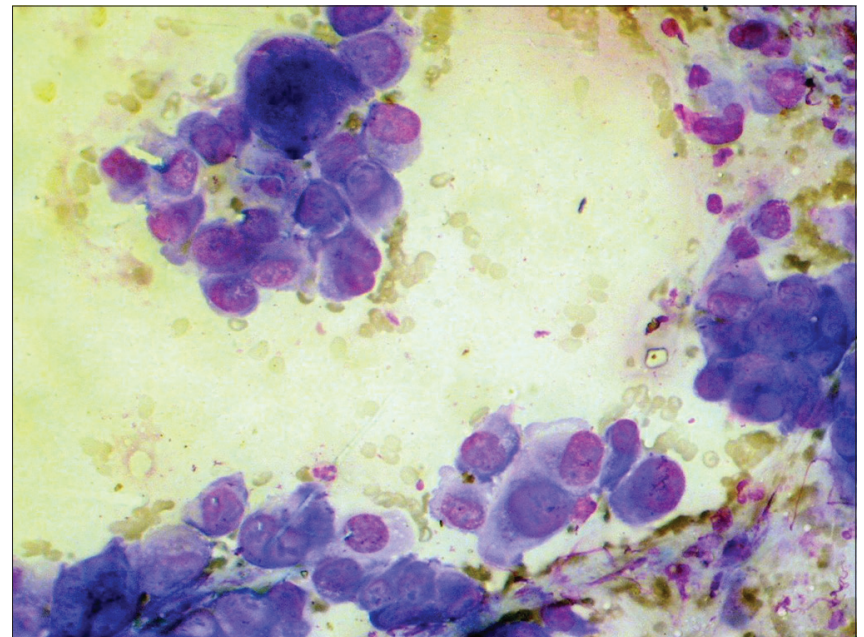

Figure 2: Photomicrograph showing cytological features of large cell anaplastic carcinoma (MGG stain, $\times 400$ magnification)

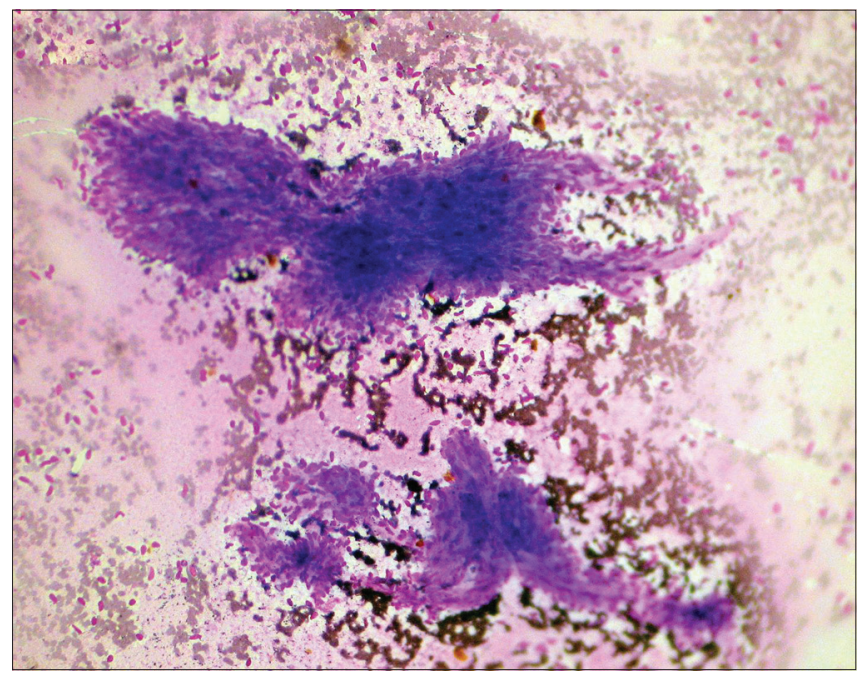

Figure 4: Photomicrograph showing cytological features of metastatic deposits in lung from a known case of fibrosarcoma (MGG stain, $\times 100$ magnification)

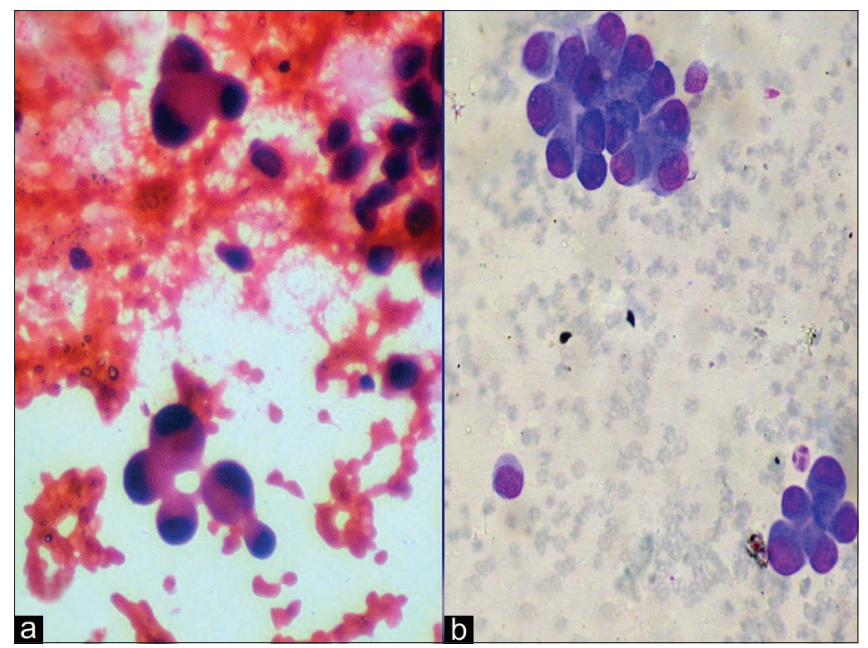

Figure 6: Photomicrograph showing cytological features suggestive of bronchioloalveolar carcinoma of lung (a) Papanicolaou stain, $\times 400$ magnification; (b) MGG stain, $\times 400$ magnification

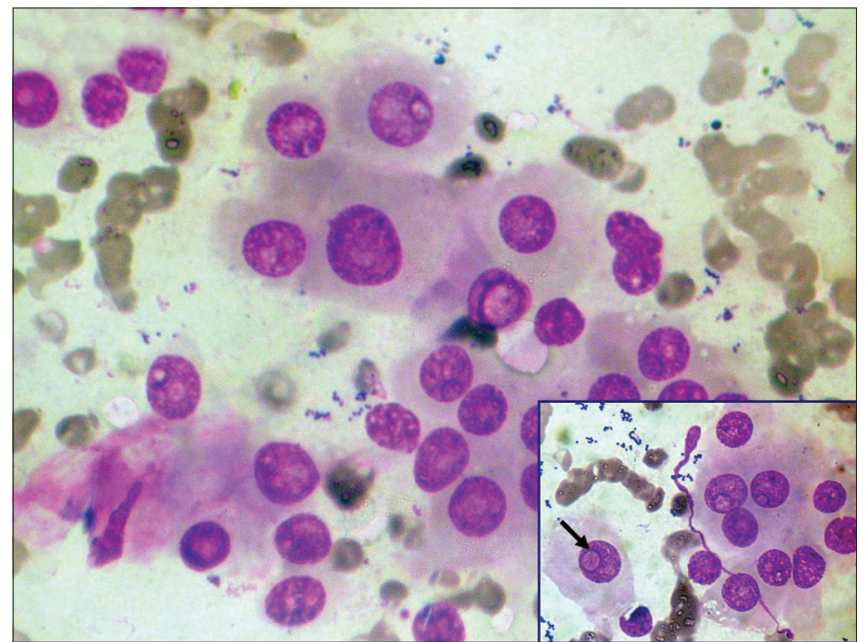

Figure 3: Photomicrograph showing metastatic deposits of hepatocellular carcinoma in lung. Inset shows polygonal cells with intranuclear inclusion (arrow) (MGG stain, $\times 400$ magnification)

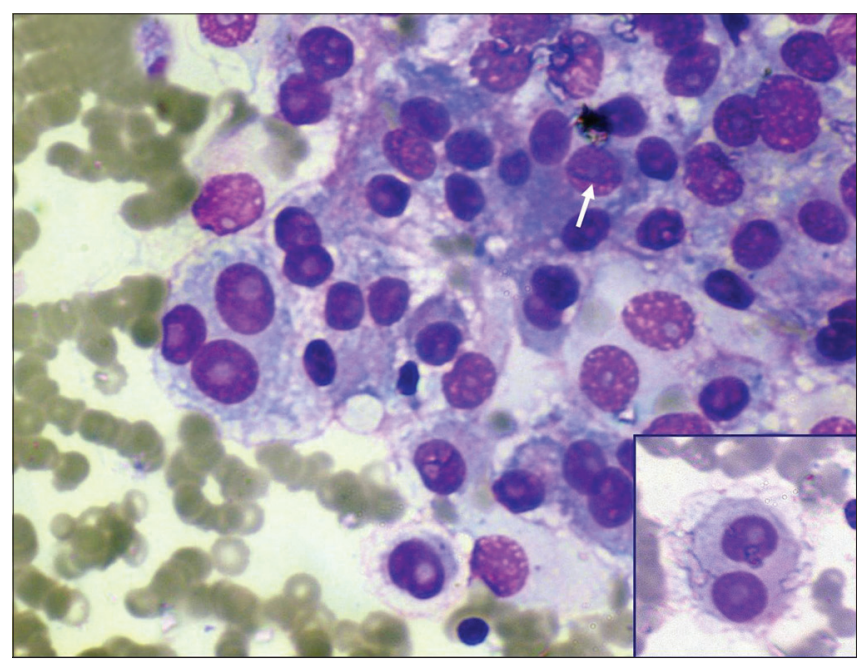

Figure 5: Photomicrograph showing metastatic deposits of malignant melanoma in lung (white arrow showing nuclear groove). Inset shows binucleate cells with prominent nucleoli (MGG stain, $\times 400$ magnification)

inclusions arranged in cell balls and clusters. Two cases $(2.1 \%)$ were diagnosed as large cell undifferentiated carcinoma in the present study. As no immunocytochemical study was done, the above cases were diagnosed as undifferentiated carcinomas with no further typing. Small cell carcinoma is the most aggressive of the common types. So, cytological typing is very crucial. In the largest series, the predictive value of a diagnosis of small cell carcinoma by fine needle biopsy $(\mathrm{FNB})$ is over $80 \%{ }^{[20,21]}$ However, there are a few series with complete histologic follow-up and some series where overall accuracy was lower. In our series, all the 8 cases $(8.3 \%)$ of small cell carcinoma diagnosed by FNAC responded to chemotherapy. Reasonable experience of cytopathologist is required before assuming the FNAC diagnosis as reliable as that of histopathology. The cytopathologist's approach to the diagnosis of metastasis by FNAC is similar to that of the surgical pathologist and requires adequate clinical history 
along with earlier cytological and histological preparations for review and comparison. ${ }^{[18]}$ One case diagnosed as sarcoma had a previous history of leg amputation due to fibrosarcoma. The previous cytological smears from the leg mass retrieved from the archives matched well with the lung aspirate. Similarly, clinical history also proved to be helpful in the cases diagnosed as seminoma, malignant melanoma, Hodgkin lymphoma, plasmacytoma and two cases of NHL. Confirming the spread of lymphoma which has been previously diagnosed may be relatively simple compared to the primary lymphoid lesions of the lungs. ${ }^{[18]}$ In a series of 13 cases of previously diagnosed Hodgkin lymphoma affecting the lung secondarily, all were diagnosed by FNAC. ${ }^{[22]}$

Perhaps the greatest advantage of fine needle aspiration is safety. However, pneumothorax remains the most common complication of CT-guided lung FNAC. ${ }^{[23]}$ Review of the existing literature reveals variable rates of pneumothorax, ranging from 5 to $64 \% \cdot{ }^{[23]}$ Location of the lesion, needle size, number of pleural passes and level of training were not correlated with pneumothorax rate. In the present study, 2 patients $(1.57 \%)$ developed pneumothorax which resolved spontaneously. One of these two patients suffered from tuberculosis, while the other was diagnosed having squamous cell carcinoma. Both these lesions were centrally located and aerated lung tissue was traversed during FNAC. Core needle biopsy $(\mathrm{CNB})$ is a relatively more invasive procedure for intrathoracic lesions with the added advantage of histopathologic examination. However, FNAC and CNB have shown comparable results for diagnosing malignant epithelial lesions, while the latter fares better in diagnosing non-epithelial malignancies and benign specific lesions. ${ }^{[24]}$

\section{CONCLUSION}

FNAC is of definite help in diagnosing intrathoracic lesions, whether malignant or inflammatory, with accuracy comparable to needle biopsies and with a reasonable rate of complication. It also avoids unnecessary thoracotomy for diagnostic purposes.

\section{REFERENCES}

1. Levine MS, Weiss JM, Harrell JH, Cameron TJ, Moser KM. Transthoracic needle aspiration biopsy following negative fiberoptic bronchoscopy in solitary pulmonary nodules. Chest 1988;93:1152-5.

2. Traill ZC, Gleeson FV. Delayed pneumothorax after CT-guided percutaneous fine needle aspiration lung biopsy. Thorax 1997;52:575-6.

3. Byrd RP Jr, Fields-Ossorio C, Roy TM. Delayed chest radiographs and the diagnosis of pneumothorax following CT-guided fine needle aspiration of pulmonary lesions. Respir Med 1999;93:379-81.

4. Santambrogio L, Nosotti M, Bellaviti N, Pavoni G, Radice F, Caputo V. CT-guided fine needle aspiration cytology of solitary pulmonary nodules: A prospective, randomized study of immediate cytologic evaluation. Chest 1997;112:423-5.

5. Westcott JL, Rao N, Colley DP. Transthoracic needle biopsy of small pulmonary nodules. Radiology 1997;202:97-103.

6. Johnsrude IS, Silverman JF, Weaver MD, McConnell RW. Rapid cytology to decrease pneumothorax incidence after percutaneous biopsy. AJR Am J Roentgenol 1985;144:793-4.

7. Roche DH, Wilsher ML, Gurley AM. Transtracheal needle aspiration. Diagn Cytopathol 1995;12:106-12.

8. Austin JH, Cohen MB. Value of having a cytopathologist present during percutaneous fine-needle aspiration biopsy of lung: Report of 55 cancer patients and metaanalysis of the literature. AJRAm J Roentgenol 1993;160:175-7.

9. Madan $M$, Bannur $H$. Evaluation of FNAC in lung diseases. Turk J Path 2010;26:1-6.

10. Gouliamos AD, Giannopoulos DH, Panagi GM, Fletoridis NK, Delieorgi-politi HA, Vlahos LJ. Computed tomography-guided fine needle aspiration of peripheral lung opacities. An initial diagnostic procedure? Acta Cytol 2000;44:344-8.

11. Damjanov I, linder J. Anderson's Pathology Vol. 1, $10^{\text {th }}$ ed. St. Louis: Mosby; 1996.

12. Bailey TM, Akhtar M, Ali MA. Fine needle aspiration biopsy in the diagnosis of tuberculosis. Acta Cytol 1985;29:732-6.

13. Gong G, Lee H, Kang GH, Shim YH, Huh J, Khang SK. Nested PCR for diagnosis of tuberculous lymphadenitis and PCR-SSCP for identification of rifampicin resistance in fine- needle aspirates. Diagn Cytopathol 2002;26:228-31.

14. Kline TS. Handbook of Fine Needle Aspiration Biopsy Cytology, $2^{\text {nd }}$ ed. New York: Churchill Livingstone; 1988.

15. Kowalewski J, Sir J, Dancewicz M, Swiniarska J, Pepliński J. Fine needle aspiration biopsy under CT-guidance-usefulness in diagnosis of malignant lung tumors. Pneumonol Alergol Pol 2004;72:177-80.

16. Wu X, Groves FD, McLaughlin CC, Jemal A, Martin J, Chen VW. Cancer incidence patterns among adolescents and young adults in the United States. Cancer Causes Control 2005;16:309-20.

17. Mondal A, Pradhan MC. Role of percutaneous fine needle aspiration cytology (FNAC) in detection of lung, pleural and mediastinal tumors - A study of 162 cases. Indian J Pathol Microbiol 1991;34:253-8.

18. Singh HK, Silverman JF. Lung, chest wall and pleura. In: Fine Needle Aspiration Cytology $4^{\text {th }}$ Ed. In: Orell SR, Sterrett GF, Whitaker D, Editors. New Delhi, India: Elsevier, Reed Elsevier India Private Limited; 2005.

19. WHO. Histological typing of lung and pleural tumours. World Health Organization International Classification of tumours. Berlin: Springer; 1999.

20. Sinner WN. Importance and value of a preoperative diagnosis in oat cell carcinoma by radiography and its verification by fine needle biopsy (FNB). Eur J Radiol 1985;5:94-8.

21. Weisbrod GL, Cunningham I, Tao LC, Chamberlain DW. Small cell anaplastic carcinoma: Cytological-histological correlations from percutaneous fine-needle aspiration biopsy. Can Assoc Radiol J 1987;38:204-8.

22. Flint A, Kumar NB, Naylor B. Pulmonary Hodgkin's disease. Diagnosis by fine needle aspiration. Acta Cytol 1988;32:221-5.

23. Cox JE, Chiles C, McManus CM, Aquino SL, Choplin RH. Transthoracic needle aspiration biopsy: Variables that affect risk of pneumothorax. Radiology 1999;212:165-8.

24. Gong Y, Sneige N, Guo M, Hicks ME, Moran CA. Transthoracic fine-needle aspiration vs oncurrent core needle biopsy in diagnosis of intrathoracic lesions: A retrospective comparison of diagnostic accuracy. Am J Clin Pathol 2006;125:438-44.

How to cite this article: Gangopadhyay M, Chakrabarti I, Ghosh N, Giri A. Computed tomography guided fine needle aspiration cytology of mass lesions of lung: Our experience. Indian J Med Paediatr Oncol 2011;32:192-6.

Source of Support: Nil, Conflict of Interest: None declared. 